\title{
Diallyl disulfide induces reversible G2/M phase arrest on a p53- independent mechanism in human colon cancer HCT-116 cells
}

\author{
HONG JAE JO ${ }^{1}$, JU DONG SONG ${ }^{2}$, KANG MI KIM ${ }^{2}$, YONG HOON CHO ${ }^{1}$, \\ KI HYUNG KIM ${ }^{3}$ and YOUNG CHUL PARK ${ }^{2}$
}

\author{
${ }^{1}$ Department of General Surgery, Medical Research Institute, Departments of ${ }^{2}$ Microbiology and Immunology, \\ and ${ }^{3}$ Obstetrics and Gynecology, Pusan National University School of Medicine, Busan 602-739, South Korea
}

Received July 9, 2007; Accepted September 12, 2007

\begin{abstract}
Diallyl disulfide (DADS), a major organosulfur compound of garlic oil, is known to have an anticancer effect on human cancer cells. However, the exact mechanisms of this anticancer activity remain unclear. Here, we investigate the effects of DADS on cell cycle progression in human colon cancer HCT-116 cells by exploring the role played by regulatory molecules such as p53 and cyclin B1. Treatment of HCT-116 cells by DADS induced a marked growth inhibition with a slight reduction in viability and induced transient cell cycle arrest in the G2/M phase. Cyclin B1 is thought to play an important role in this process, as the DADS-induced G2/M phase arrest occurs with the increase of cyclin B1 expression. DADS also significantly induced the expression of $\mathrm{p} 53$, which contributes to cell cycle arrest in cancer cells, at a late timepoint of $24 \mathrm{~h}$. In addition, knockdown of p53 by siRNA did not affect cell cycle arrest, its reversibility, or the expression of cyclin B1 in the G2/M phase induced by DADS. Based on these results we conclude that, with the dynamic expression of cyclin B1, DADS induces reversible cell cycle arrest in the G2/M phase of HCT-116 cells through a p53-independent mechanism.
\end{abstract}

\section{Introduction}

Epidemiological studies show that the intake of garlic is closely related to the reduction of various cancers, such as stomach, colorectal and prostate cancer (1-4). Garlic and its organosulfur compounds are becoming more appealing as anticarcinogenic agents due to their ability to induce apoptosis (5) and inhibit both the initiation and promotion stages of tumorigenesis in animal studies $(6,7)$. These organosulfur compounds, formed by enzymatic activity when garlic is minced or crushed, probably account for most of the anti-

Correspondence to: Dr Young Chul Park, Department of Microbiology and Immunology, Pusan National University School of Medicine, Busan 602-739, South Korea

E-mail: ycpark@pusan.ac.kr

Key words: diallyl disulfide, HCT-116 cells, G2/M arrest, p53, cyclin B1 carcinogenic effects of garlic. Among them is diallyl disulfide (DADS), an oil-soluble compound which is present at very high concentrations in garlic-derived extracts. Recently, several reports have shown that DADS modulates cell cycles in several cancer cell lines (8-11). However, the molecular targets or signaling mechanisms underlying this DADSinduced cell cycle arrest are not as yet fully understood.

Cell cycles are closely regulated, physiologically, by cyclin-dependent kinases (CDKs) and CDK inhibitors (12). Their disruption contributes to the anticarcinogenic effects of naturally occurring anticancer drugs. Cell cycle arrest, an important mechanism in the maintenance of genomic integrity, affords time for the repair of damaged DNA or the activation of apoptosis in cases of severe damage (13-15). Current evidence suggests that the tumor suppressor p53 acts as a checkpoint regulator of cell cycles, contributing to cell cycle arrest in the G1 $(15,16)$ and G2 (17-19) phases by a multitude of molecular pathways, in several cancer cells. In particular, cell cycle arrest in the G2/M phase is known to be mediated by the inhibition of cyclin B1-cdc2 activity. Moreover, recent reports have shown that DADS induces p53 expression in colon cancer HCT-116 cells with wild-type p53 (20), as well as in other cancer cell lines (21-23).

In this study, we investigated DADS-induced cell cycle arrest, accompanied by the induction of wild-type p53 and cyclin B1, in the G2/M phase of HCT-116 colon cancer cells, and looked for possible relationships between these factors. Our results show that DADS, independently of $\mathrm{p} 53$, induces reversible G2/M arrest in HCT-116 cells via the activation of cyclin B1.

\section{Materials and methods}

Reagents. DADS was purchased from Fluka Chemika Co. (Bucha, Switzerland). Protease inhibitor cocktail, dimethyl sulfoxide (DMSO), trypan blue (0.4\%) and propidium iodide (PI) were obtained from Sigma-Aldrich Chemical Co. (St. Louis, MO). Anti-p53 and B-actin antibodies were purchased from Santa Cruz Biotechnology (Santa Cruz, CA). Anti-cyclin A, cyclin B1 and cdc2 antibodies were obtained from Cell Signaling (Beverly, MA). Secondary horseradish peroxidase (HRP)-conjugated antibodies and enhanced chemiluminescence (ECL) Western blotting kits were obtained from Amersham Pharmacia Biotech (Piscataway, NJ). Fetal bovine 
serum (FBS), HBSS, and other tissue culture reagents were purchased from Life Technologies (Gaithersburg, MD).

Cell culture. Human colon cancer HCT-116 cells were obtained from the American Tissue Culture Collection (Rockville, MD) and cultured in DMEM supplemented with $10 \%$ heat-inactivated FBS and antibiotics $(100 \mathrm{U} / \mathrm{ml}$ penicillin, $100 \mu \mathrm{g} / \mathrm{ml}$ streptomycin) at $37^{\circ} \mathrm{C}$ in a $5 \% \mathrm{CO}_{2}$ atmosphere. To maintain reproducibility, confluent cells were subcultured according to standard protocol with $0.01 \%$ trypsin-EDTA. DADS was dissolved in DMSO prior to its addition to the cultures. As a control, an equal amount of DMSO $(<0.03 \%)$ was added to untreated cells.

Cell viability and growth analysis. HCT-116 cells were plated at $1 \times 10^{5}$ cells per $60-\mathrm{mm}$ dish and incubated for $12 \mathrm{~h}$. Cells were cultured in the presence or absence of different concentrations of DADS in fresh DMEM supplemented with $10 \%$ FBS. After being incubated for different periods of time, the cells were washed with cold phosphate-buffered saline (PBS), trypsinized, rinsed in medium containing FBS and centrifuged at $500 \mathrm{x}$ g. Cells were then resuspended in medium and viable and dead cells were counted by the trypan blue dye exclusion method using a hemocytometer.

Cell cycle analysis by flow cytometry. Cells ( $1 \times 10^{6}$ cells/well) were cultured in 6-well plates in medium containing $10 \%$ FBS then treated with or without $200 \mu \mathrm{M}$ of DADS, for different periods of time, in control or transfected cells (24). The cells were then harvested, washed in ice-cold PBS and fixed with $70 \%$ ethanol/PBS at $4^{\circ} \mathrm{C}$. The fixed cells were incubated with $0.5 \mathrm{ml}$ PBS containing $20 \mu \mathrm{g} / \mathrm{ml} \mathrm{RNase}$ A for $30 \mathrm{~min}$ at $37^{\circ} \mathrm{C}$, and stained with $50 \mu \mathrm{g} / \mathrm{ml}$ PI for $30 \mathrm{~min}$ in the dark at room temperature. Finally, cells were analyzed with a FACSCalibur $^{\mathrm{TM}}$ flow cytometer (Becton Dickinson, San Jose, CA). A minimum of $1 \times 10^{4}$ cells per sample was evaluated, and the percentage of cell distributions at each phase of the cell cycle was further calculated by CellQuest and ModFit (Becton Dickinson) software (25).

Western blot analysis. Equivalent amounts of lysates were loaded onto $10 \%$ SDS/PAGE. The gel was transferred onto a nitrocellulose membrane using an electroblotting apparatus (Bio-Rad, Richmond) and was reacted with primary mouse monoclonal anti-p53, p21 and cyclin B1 antibodies according to standard methods. It was further incubated with a secondary goat anti-mouse immunoglobulin G conjugated with HRP. Bound immunocomplexes were visualized on X-ray film by ECL reagents (Amersham Pharmacia Biotech). B-actin was used as an internal control to monitor equal protein sample loading.

Transfection of siRNA. Twenty-one nucleotide RNA with 3'dTdT overhangs were synthesized to interfere exclusively with p53 mRNA by Ambion (Austin, TX), in the 'ready-to-use' option, as previously described (26). As a negative control, the same nucleotides were scrambled to form a non-genomic combination (controlled by a basic local alignment search tool). The targets of the AA-N19 mRNA were p53 with a target sequence of 5'-GACUCCAGTGGUAAUCUAC-3'. Cells in

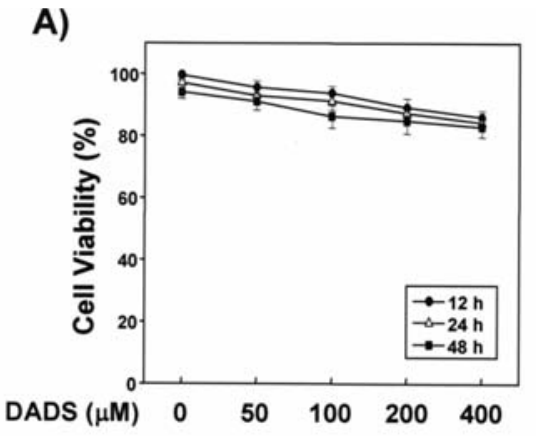

B)

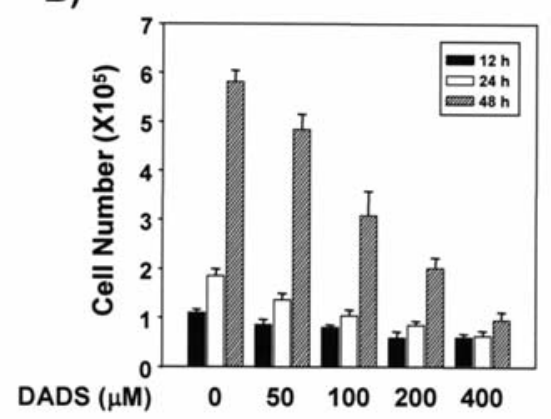

Figure 1. Effect of DADS on cell viability and growth in human colon cancer HCT-116 cells. Cells were plated at $1 \times 10^{5}$ cells per $60-\mathrm{mm}$ dish, incubated for $12 \mathrm{~h}$, transfered to fresh medium and treated with different concentrations of DADS for 12, 24, and $48 \mathrm{~h}$, as indicated. After treatment, cells were collected, trypsinized and washed with PBS at each time-point. Viable cells were scored by hemocytometer counts of trypan blue-excluding cells. (A) Measurement of cell viability, determined as a percentage of total cells. (B) Numbers of viable cells. Data shown are the mean \pm SE obtained from three independent experiments.

the exponential phase of growth were plated in 6-well plates at $5 \times 10^{5}$ cells/well, grown for $24 \mathrm{~h}$, and then transfected with $30 \mathrm{nM}$ of siRNA per well using siPORT Amine and OptiMEM media, according to the manufacturer's recommended protocol.

Statistics or reproducibility. Each experiment was performed at least three times. Statistical values were expressed as the mean \pm standard error (SE) of the means obtained from each independent experiment. The data from the experimental and control groups were tested for statistical significance by a one-tailed Student's t-test, and $\mathrm{P}<0.05$ was accepting as the level of significance.

\section{Results}

$D A D S$ suppresses proliferation in human colon cancer HCT-116 cells. We first determined the effect of DADS, a major organosulfur compound in garlic, on the proliferation of HCT-116 cells. Cells were treated with various concentrations of DADS $(50,100,200$, and $400 \mu \mathrm{M})$ for different periods of time, and trypan blue dye exclusion methods were performed at the end of each treatment. Cells did not exhibit significant decreased cellular viability after 12,24 , and $48 \mathrm{~h}$ with DADS, even at high concentrations (Fig. 1A). However, a marked reduction in viable cell count was observed after 24 and $48 \mathrm{~h}$ of treatment with dose-dependent concentrations of DADS (Fig. 1B). This suggests that the exposure of HCT-116 cells 
A)

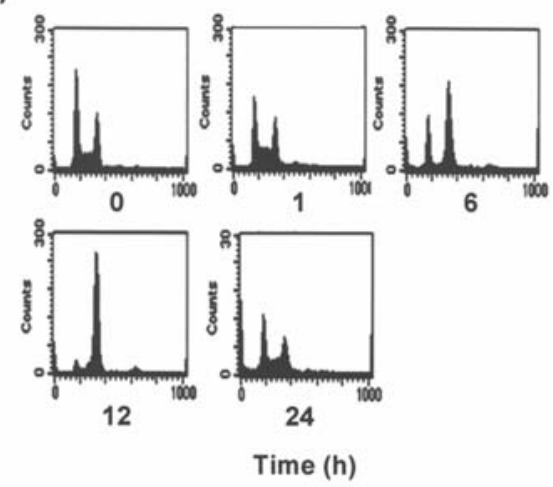

B)

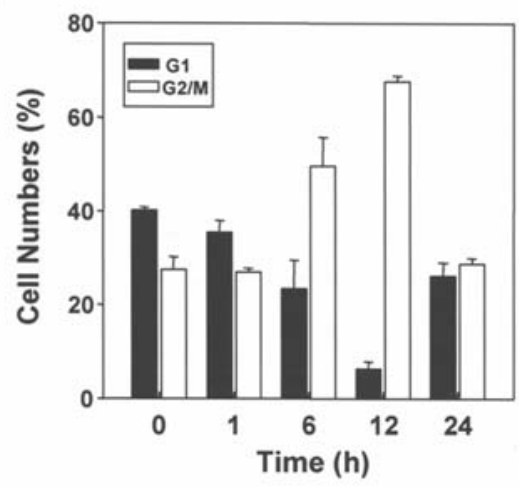

Figure 2. Effect of DADS on cell cycle distribution in HCT-116 cells. Cells $\left(1 \times 10^{6}\right)$ were treated with $200 \mu \mathrm{M}$ DADS for $1,6,12$ and $24 \mathrm{~h}$. (A) Flow cytometric analysis of cell cycle distribution. After incubation for different periods of time, cells were collected, stained and analyzed by flow cytometry for cell distribution at each phase of the cell cycle. (B) Calculation of cell cycle distribution using CellQuest and ModFit software. Data are the means \pm SE obtained from a triplicate of each experiment.

to DADS results in a marked decrease in cell proliferation, without significant toxicity for necrotic cell death.

$D A D S$ stimulates cell cycle arrest in the G2/M phase. To determine whether growth inhibition induced by DADS is associated with the arrest of cells in a particular phase, we analyzed cell distributions at each phase of the cell cycle by flow cytometry. In untreated cells, $35-45 \%$ of cells were in the G1 and $25-30 \%$ in the G2/M phase. As expected, DADS resulted in a significant accumulation of cells in the G2/M phase, with a dramatic loss of cells in the G1 and S phases. However, the peak of arrested cell population in the G2/M phase was observed at $12 \mathrm{~h}$ following treatment with DADS, and cells regained an almost normal cell cycle pattern at $24 \mathrm{~h}$ without the removal of DADS (Fig. 2).

DADS induces p53 expression in HCT-116 cells at a late timepoint. To determine whether the growth inhibition and cell cycle arrest induced by DADS in HCT-116 cells is correlated with p53, we examined the amount of expressed p53 using Western blotting. DADS markedly induced the expression of p53 at $24 \mathrm{~h}$ in a dose-dependent manner (Fig. 3A). Surprisingly, as shown in Fig. 3B, a significantly increased level of p53 was only detected at $24 \mathrm{~h}$ following treatment with DADS. This suggests that up-regulated p53 is not involved in the regulatory mechanisms of DADS-induced G2/M phase arrest.
A)

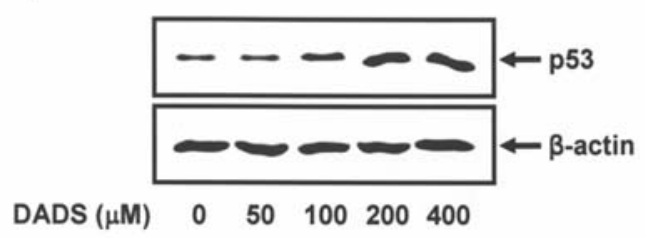

B)

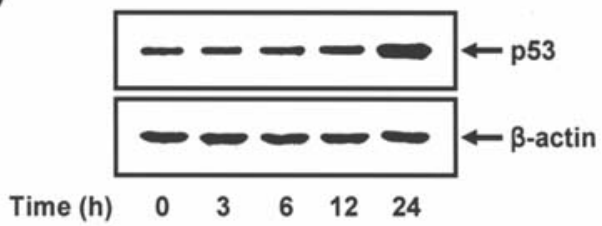

Figure 3. Effect of DADS on p53 expression in HCT-116 cells. (A) Dosedependent experiment with DADS for p53 expression. Cells were treated with different concentrations of DADS for $24 \mathrm{~h}$. (B) Time course of $\mathrm{p} 53$ expression induced by DADS. Cells were treated with $200 \mu \mathrm{M}$ DADS for 3, 6, 12 and $24 \mathrm{~h}$, as indicated. Whole cell extracts were analyzed by Western blotting using antibody for p53. B-actin was used as an internal control to monitor equal protein loading.

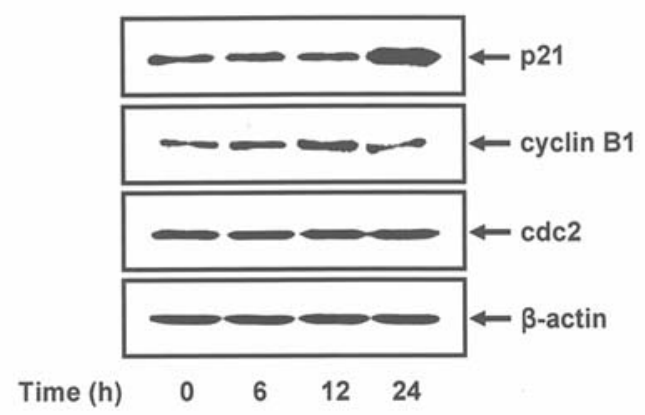

Figure 4. Effect of DADS on the expression of p21, cyclin B1 and cdc2 in HCT-116 cells. Cells were treated with $200 \mu \mathrm{M}$ DADS for 6, 12 and $24 \mathrm{~h}$, as indicated. Whole cell extracts were analyzed by Western blotting using corresponding antibodies. $\beta$-actin was used as an internal control to monitor equal protein loading.

We also analyzed the expression of cell cycle regulatory molecules at the G2/M boundary, such as cyclin B1 and cdc2, whose expressions are induced in cells entering the $\mathrm{M}$ from the G2 phase. p21 levels, which regulate cell cycle progression in cells with normal p53, were raised only at $24 \mathrm{~h}$ following treatment with DADS, as a downstream response to p53. Unlike anticancer drugs that induce cell cycle arrest in the G2/M phase, the expression of cyclin B1 was markedly induced until $12 \mathrm{~h}$ following DADS treatment. Interestingly, the reversibility of the cell cycle observed at $24 \mathrm{~h}$ following DADS treatment was accompanied by a decrease in cyclin B1 (Fig. 4). This result shows that DADS-induced arrest in the G2/M phase occurs with an increase in cyclin B1 expression.

p53 is not associated with G2/M phase arrest/maintenance and its reversibility in DADS-treated HCT-116 cells. Flatt et al (17) reported that $\mathrm{p} 53$ prevents premature exit from G2 arrest through the inhibition, following genotoxic stress, of cyclin 
A)
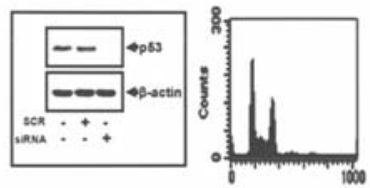

Control

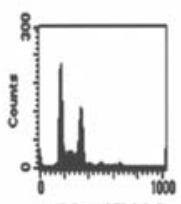

p53 siRNA

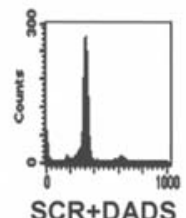

B)

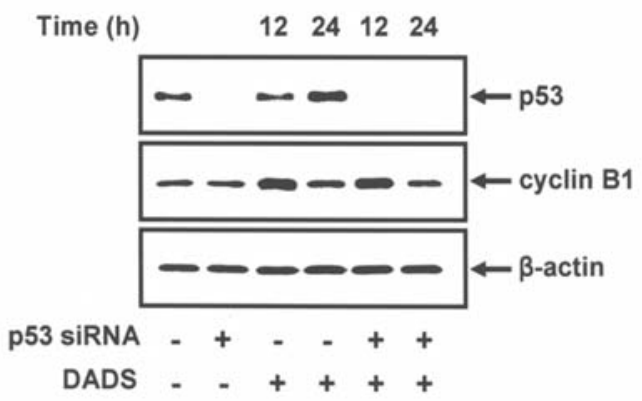

Figure 5. Effects of p53 siRNA on cell cycle distribution and cyclin B1 expression in DADS-treated HCT-116 cells. Cells were transfected with siRNA for the silencing of the p53 gene and then incubated in the presence or absence of $200 \mu \mathrm{M}$ DADS for 12 or $24 \mathrm{~h}$. (A) Flow cytometric analysis of cell cycle distribution. Box, stable suppression of $\mathrm{p} 53$ expression by siRNA. After transfection of 553 with siRNA, cell lysates were analyzed by Western blotting using antibody for p53. (B) Expression of cyclin B1. Cell lysates were analyzed by Western blotting using antibody for p53 and cyclin B1. $\beta$-actin was used as an internal control to monitor equal protein loading.

B1-cdc2 activity in HCT-116 cells. We further investigated the role of resident p53 on cell cycle arrest/maintenance and its reversibility by DADS in HCT-116 cells, which express functional wild-type p53. We used oligonucleotides, which interfere with p53 mRNA (siRNA), for the knockdown of p53 expression. siRNA efficiently silenced the p53 gene and completely suppressed p53 levels (Fig. 5A, box). Importantly, silencing the p53 gene did not affect cell cycle arrest in the G2/M phase induced by DADS (Fig. 5A). Moreover, cell cycle arrest brought on by DADS reverted to the normal cell cycle pattern at $24 \mathrm{~h}$ in p53-deficient HCT-116 cells, compared with the control cells treated with DADS (data not shown). This demonstrates that p53 is not associated with cell cycle arrest and its reversibility in DADS-treated HCT-116 cells. Finally, to determine whether the increase and decrease of cyclin B1 in DADS-treated HCT-116 cells is correlated with p53, we analyzed the pattern of cyclin B1 expression following the knockdown of p53 by siRNA. As shown in Fig. 5B, the knockdown of p53 did not affect the expression pattern of cyclin B1 in DADS-treated cells. The data suggest that cyclin $\mathrm{B} 1$ acts as an important regulator of the transition from the $\mathrm{G} 2$ to the $\mathrm{M}$ phase and of the reversibility of p53-independently arrested cells in HCT-116 cells treated with DADS .

\section{Discussion}

A chemopreventive and/or chemotherapeutic use of phytochemicals could open new avenues in the search for strategies against the proliferation of cancer cells. Numerous biologically active phytochemicals kill cancer cells by disrupting the cell cycle, which is tightly regulated by a series of cell cycle regulators. Cell cycle arrest, promoted by the failure of cell cycle progression, affords time for the maintenance of genomic integrity in response to DNA damage. Several reports have revealed that garlic and its derivatives are associated with anticarcinogenic action $(3,5-7)$, and the anticarcinogenic effects of sulfur-containing compounds have been widely reported $(7,10,27)$. Among the organosulfur compounds of garlic derivatives, DADS is known to be the most important in researching the potential effects of garlic.

Tumor suppressor p53 is a nuclear transcription factor that is elevated in response to DNA damage and has a critical function in the maintenance of the integrity of the genome. Mutational inactivation of p53 has been found to be involved in $>50 \%$ of human cancers, which indicates the importance of p53 in human carcinogenesis (28). p53 is activated in response to stimuli such as $\mathrm{UV}$, ionizing radiation, hypoxia and numerous anticancer drugs. It has many known functions, but its main anticarcinogenic activity is the ability to prevent cell growth by activating cell cycle arrest in both the G1 and G2 phases $(15-19,29,30)$. Recent reports also show that the activation of p53 to induce cell cycle arrest correlates well with its ability to function as a transcriptional factor (31) and depends on the activation of the CDK inhibitor p21 (32,33). p21 activates cell cycle arrest identical to that seen in response to p53 (34).

In the present study, we show that DADS induces transient cell cycle arrest in the G2/M phase of human colon cancer HCT-116 cells based on a p53-independent mechanism. A few reports have shown that DADS induces both cell cycle arrest and apoptosis in other cancer cells as well, such as adenocarcinoma AGS (22), neuroblastoma SH-SY5Y (35), bladder cancer T24 (36), lung carcinoma A549 (9) and, in particular, colon cancer p53 mutant SW480 cells (10). Other reports have demonstrated that several anticarcinogenic agents induce p53-mediated cell cycle arrest in the $\mathrm{G} 1$ or $\mathrm{G} 2 / \mathrm{M}$ phase of colon cancer p53 wild-type HCT-116 cells $(16,18,37)$. However, the molecular mechanisms by which DADS induces cell cycle arrest in the $\mathrm{G} 1$ or $\mathrm{G} 2 / \mathrm{M}$ phase remain poorly understood. Therefore, we investigated the effect of DADS on cell cycle progression in HCT-116 cells containing wild-type p53, and explored the effects of regulatory molecules such as p53 and cyclin B1.

Compared to other cells treated with DADS, treatment of HCT-116 cells resulted in a marked decrease in cell proliferation without significant toxicity. As in other reports, a significant accumulation of HCT-116 cells in the G2/M phase was also observed when the cells were exposed to DADS. However, the peak of cell population arrest in the G2/M phase was disrupted at $24 \mathrm{~h}$ following treatment with DADS (Fig. 2). As described above, we thought the activation state of p53 could be related to cell cycle arrest in DADS-treated HCT-116 cells. Surprisingly, the level of p53 protein was only increased at late time-point of $24 \mathrm{~h}$ following DADS treatment. To 
further confirm this result, we performed p53 siRNA-mediated gene silencing experiments. Silencing the p53 gene did not affect cell cycle arrest in the G2/M phase induced by DADS (Fig. 5A). As well, cell cycle arrest brought on by DADS reverted to the normal cell cycle pattern at $24 \mathrm{~h}$ in p53-deficient cells. These data clearly show that p53 is not involved in the regulatory mechanisms of DADS-induced G2/M phase arrest and its reversibility in HCT-116 cells. On the other hand, the kinetics of cyclin B1 and cdc2 levels are correlated with cell cycle arrest in the G2/M phase. Other reports have shown that the inhibitory effect of $\mathrm{p} 53$ on cyclin $\mathrm{B} 1$ gene expression alone can contribute significantly to the regulation of the $\mathrm{G} 2 / \mathrm{M}$ checkpoint $(19,38,39)$. In fact, p53 regulates the level of cyclin B1 through a transcriptional repression that is not completely understood $(40,41)$. Nevertheless, our results show that the expression of cyclin B1 was markedly induced until $12 \mathrm{~h}$ following DADS treatment. Usually, the up-regulation of the cyclin B1-cdc2 complex induces cell cycle arrest in the midmetaphase of mitosis (43). Interestingly, cell cycle reversibility observed at $24 \mathrm{~h}$ following DADS treatment was accompanied by a decrease in cyclin B1 (Fig. 4). In addition, the knockdown of p53 did not affect the expression pattern of cyclin B1 in DADS-treated cells (Fig. 5B). These data suggest that cyclin B1 acts as an important regulator of the transition from the G2 to the $\mathrm{M}$ phase and of the reversibility of p53-independently arrested cells in DADS-treated HCT-116 cells.

In conclusion, we have demonstrated that, in HCT-116 cells, DADS induces cell cycle arrest in the G2/M phase along with the activation of cyclin B1, and also induces its reversibility along with the inhibition of cyclin B1. This is not associated with the induction of p53 expression, suggesting that other signaling pathways leading to cell cycle arrest and its reversibility are involved. Studies focusing on the cell cycle progression of DADS would provide insight into the complicated process of cell cycle regulation, and would lead to an exploration of the molecular mechanisms of DADS chemotherapeutic potency in human cancer. Further studies on HCT-116 cells, as well as on p53-defective cell lines, are needed in order to understand the mechanisms behind the anticarcinogenic effect of DADS on colon cancer cells.

\section{Acknowledgements}

This study was supported by a Medical Research Institute Grant (2006-17), Pusan National University.

\section{References}

1. You WC, Blot WJ, Chang YS, Ershow A, Yang ZT, An Q, Henderson BE, Fraumeni JF and Wang TG: Allium vegetables and reduced risk of stomach cancer. $J$ Natl Cancer Inst 81: 162-164, 1989.

2. Dorant E, van den Brandt PA and Goldbohm RA: A prospective cohort study on the relationship between onion and leek consumption, garlic supplement use and the risk of colorectal carcinoma in The Netherlands. Carcinogenesis 17: 477-484, 1996.

3. Hsing AW, Chokkalingam AP, Gao YT, Madigan MP, Deng J, Gridley $G$ and Fraumeni JF: Allium vegetables and risk of prostate cancer: a population-based study. J Natl Cancer Inst 94: 1648-1651, 2002.

4. Fleischauer AT and Arab L: Garlic and cancer: a critical review of the epidemiologic literature. J Nutr 131: S1032-S1040, 2001.

5. Sundaram SG and Milner JA: Diallyl disulfide induces apoptosis of human colon tumor cells. Carcinogenesis 17: 669-763, 1996.
6. Singh SV, Mohan RR, Agarwal R, Benson PJ, Hu X, Rudy MA, Xia H, Katoh A, Srivastava SK, Mukhtar H, Gupta V and Zaren HA: Novel anti-carcinogenic activity of an organosulfide from garlic: inhibition of H-RAS oncogene transformed tumor growth in vivo by diallyl disulfide is associated with inhibition of p21H-ras processing. Biochem Biophys Res Commun 225: 660-665, 1996.

7. Srivastava SK, Hu X, Xia H, Zaren HA, Chatterjee ML, Agarwal R and Singh SV: Mechanism of differential efficacy of garlic organosulfides in preventing benzo(a)pyrene-induced cancer in mice. Cancer Lett 118: 61-67, 1997.

8. Nakagawa H, Tsuta K, Kiuchi K, Senzaki H, Tanaka K, Hioki K and Tsubura A: Growth inhibitory effects of diallyl disulfide on human breast cancer cell lines. Carcinogenesis 22: 891-897, 2001.

9. Wu XJ, Kassie F and Mersch-Sundermann Y: The role of reactive oxygen species (ROS) production on diallyl disulfide (DADS) induced apoptosis and cell cycle arrest in human A549 lung carcinoma cells. Mutat Res 579: 115-124, 2005.

10. Xiao D, Pinto JT, Gundersen GG and Weinstein IB: Effects of a series of organosulfur compounds on mitotic arrest and induction of apoptosis in colon cancer cells. Mol Cancer Ther 4: 1388-1398, 2005.

11. Milner JA: Significance of garlic and its constituents in cancer and cardiovascular disease: Preclinical perspectives on garlic and cancer. J Nutr 136: S827-S831, 2006.

12. Morgan DO: Principles of CDK regulation. Nature 374: 131-134, 1995 .

13. Kaufmann WK and Paules RS: DNA damage and cell cycle checkpoints. FASEB J 10: 238-247, 1996.

14. Bunz F, Dutriaux A, Lengauer C, Waldman T, Zhou S, Brown JP, Sedivy JM, Kinzler KW and Vogelstein B: Requirement for p53 and p21 to sustain G2 arrest after DNA damage. Science 282: 1497-1501, 1998.

15. Eastman A: Cell cycle checkpoints and their impact on anticancer therapeutic strategies. J Cell Biochem 91: 223-231, 2004.

16. Meng LH, Zhang H, Hayward L, Takemura H, Shao RG and Pommier Y: Tetrandrine induces early G1 arrest in human colon carcinoma cells by down-regulating the activity and inducing the degradation of G1-S-specific cyclin-dependent kinases and by inducing p53 and p21Cip1. Cancer Res 64: 9086-9092, 2004.

17. Flatt PM, Tang LJ, Scatena CD, Szak ST and Pietenpol JA: p53 regulation of $\mathrm{G} 2$ checkpoint is retinoblastoma protein dependent. Mol Cell Biol 20: 4210-4223, 2000.

18. Chen Y, Miao ZH, Zhao WM and Ding J: The p53 pathway is synergized by $\mathrm{p} 38$ MAPK signaling to mediate $11,11^{\prime}$-dideoxyverticillin-induced G2/M arrest. FEBS Lett 579: 3683-3690, 2005.

19. Ianzini F, Bertoldo A, Kosmacek EA, Phillips SL and Mackey MA: Lack of 553 function promotes radiation-induced mitotic catastrophe in mouse embryonic fibroblast cells. Cancer Cell Int 6: 11, 2006.

20. Bottone FG Jr, Baek SJ, Nixon JB and Eling TE: Diallyl disulfide (DADS) induces the antitumorigenic NSAID-activated gene (NAG-1) by a p53-dependent mechanism in human colorectal HCT 116 cells. J Nutr 132: 773-778, 2001.

21. Hong YS, Ham YA, Choi JH and Kim J: Effects of allyl sulfur compounds and garlic extract on the expressions of Bcl-2, Bax, and p53 in non small cell lung cancer cell lines. Exp Mol Med 32: $127-134,2000$.

22. Filomeni G, Aquilano K, Rotilio G and Ciriolo MR: Glutathionerelated systems and modulation of extracellular signal-regulated kinases are involved in the resistance of AGS adenocarcinoma gastric cells to diallyl disulfide-induced apoptosis. Cancer Res 65: 11735-11742, 2005

23. De Martino A, Filomeni G, Aquilano K, Ciriolo MR and Rotilio G: Effects of water garlic extracts on cell cycle and viability of HepG2 hepatoma cells. J Nutr Biochem 17: 742-749, 2006.

24. Ormerod MG: Flow Cytometry: A Practical Approach. Oxford University Press, New York, pp69-81, 1990.

25. Wang XW, Zhan Q, Coursen JD, Khan MA, Kontny HU, Yu L, Hollander MC, O'Connor PM, Fornace AJ and Harris CC: GADD45 induction of a G2/M cell cycle checkpoint. Proc Natl Acad Sci USA 96: 3706-3711, 1999

26. Park SE, Song JD, Kim KM, Park YM, Kim ND, Yoo YH and Park YC: Diphenyleneiodonium induces ROS-independent p53 expression and apoptosis in human RPE cells. FEBS Lett 581: 180-186, 2007.

27. Wu X, Kassie F and Mersch-Sundermann V: Induction of apoptosis in tumor cells by naturally occurring sulfur-containing compounds. Mutat Res 589: 81-102, 2005. 
28. Levine AJ: p53, the cellular gatekeeper for growth and division. Cell 88: 323-331, 1997.

29. Agarwal ML, Agarwal A, Taylor WR and Stark GR: p53 controls both the G2/M and the G1 cell cycle checkpoints and mediates reversible growth arrest in human fibroblasts. Proc Natl Acad Sci USA 92: 8493-8497, 1995.

30. Bates S, Hickman ES and Vousden KH: Reversal of p53-induced cell-cycle arrest. Mol Carcinog 24: 7-14, 1999.

31. Rowan S, Ludwig RL, Haupt Y, Bates S, Lu X, Oren M and Vousden KH: Specific loss of apoptotic but not cell-cycle arrest function in a human tumor derived p53 mutant. EMBO J 15: 827-838, 1996.

32. Brugarolas J, Chandrasekaran C, Gordon JI, Beach D, Jacks T and Hannon GJ: Radiation-induced cell cycle arrest compromised by $\mathrm{p} 21$ deficiency. Nature 377: 552-557, 1995.

33. Waldman T, Kinzler KW and Vogelstein B: p21 is necessary for the p53-mediated G1 arrest in human cancer cells. Cancer Res 55: 5187-5190, 1995.

34. Niculescu AB III, Chen X, Smeets M, Hengst L, Prives C and Reed SI: Effects of p21Cip1/Waf1 at both the G1/S and the G2/M cell cycle transitions: $\mathrm{pRb}$ is a critical determinant in blocking DNA replication and in preventing endoreduplication. Mol Cell Biol 18: 629-643, 1998.

35. Filomeni G, Aquilano K, Rotilio G and Ciriolo MR: Reactive oxygen species-dependent c-Jun NH2-terminal kinase/c-Jun signaling cascade mediates neuroblastoma cell death induced by diallyl disulfide. Cancer Res 63: 5940-5949, 2003.
36. Lu HF, Sue CC, Yu CS, Chen SC, Chen GW and Chung JG Diallyl disulfide (DADS) induced apoptosis undergo caspase-3 activity in human bladder cancer T24 cells. Food Chem Toxicol 42: 1543-1552, 2004.

37. Goel A, Fuerst F, Hotchkiss E and Boland CR: Selenomethionine induces p53 mediated cell cycle arrest and apoptosis in human colon cancer cells. Cancer Biol Ther 5: 529-535, 2006.

38. Innocente SA, Abrahamson JLA, Cogswell JP and Lee JM: p53 regulates a G2 checkpoint through cyclin B1. Proc Natl Acad Sci USA 96: 2147-2152, 1999.

39. Park M, Chae HD, Yun J, Jung M, Kim YS, Kim SH, Moon HH and Shin DY: Constitutive activation of cyclin B1-associated cdc2 kinase overrides p53-mediated G2/M arrest. Cancer Res 60: 542-545, 2000

40. Taylor WR, Agarwal ML, Agarwal A, Stacey DW and Stark GR: p53 inhibits entry into mitosis when DNA synthesis is blocked Oncogene 18: 283-295, 1999.

41. Taylor WR and Stark GR: Regulation of the G2/M transition by p53. Oncogene 20: 1803-1815, 2001.

42. Wolf F, Wandke C, Isenberg N and Geley S: Dose-dependent effects of stable cyclin B1 on progression through mitosis in human cells. EMBO J 25: 2802-2813, 2006. 